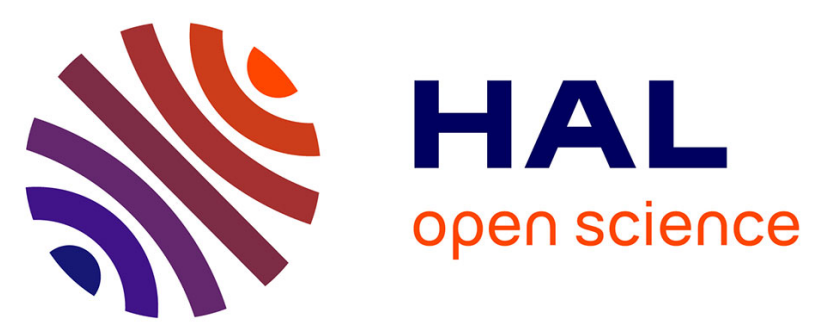

\title{
A case-control study of risk factors for intussusception among infants in eastern France after the introduction of the rotavirus vaccine
}

\author{
Arnaud Fotso Kamdem, Chrystelle Vidal, Lionel Pazart, Franck Leroux, \\ Aurore Pugin, Caroline Savet, Geoffroy Sainte-Claire Deville, Didier \\ Guillemot, Jacques Massol
}

\section{To cite this version:}

Arnaud Fotso Kamdem, Chrystelle Vidal, Lionel Pazart, Franck Leroux, Aurore Pugin, et al.. A casecontrol study of risk factors for intussusception among infants in eastern France after the introduction of the rotavirus vaccine. Vaccine, 2019, 37 (32), pp.4587 - 4593. 10.1016/j.vaccine.2019.02.053 . hal-03488159

\author{
HAL Id: hal-03488159 \\ https://hal.science/hal-03488159
}

Submitted on 20 Dec 2021

HAL is a multi-disciplinary open access archive for the deposit and dissemination of scientific research documents, whether they are published or not. The documents may come from teaching and research institutions in France or abroad, or from public or private research centers.
L'archive ouverte pluridisciplinaire HAL, est destinée au dépôt et à la diffusion de documents scientifiques de niveau recherche, publiés ou non, émanant des établissements d'enseignement et de recherche français ou étrangers, des laboratoires publics ou privés.

\section{(ㄷ)(1) $\$$}

Distributed under a Creative Commons Attribution - NonCommerciall 4.0 International 


\section{A Case-Control Study of Risk Factors for Intussusception Among Infants in Eastern France after the Introduction of the Rotavirus Vaccine}

\section{Author names and affiliations:}

\section{Arnaud Fotso Kamdem, MD, PhD}

Department of Pediatric Surgery

Besançon University Hospital

F-25000 Besançon, France

E-mail : afotsokamdem@chu-besancon.fr

\section{Chrystelle Vidal, MSc}

INSERM-CIC-1431

Besançon University Hospital

F-25000 Besançon, France

E-mail : c1vidal@chu-besancon.fr

\section{Lionel Pazart, MD}

INSERM-CIC-1431

Besançon university hospital

F-25000 Besançon, France

E-mail : lpazart@chu-besancon.fr

Franck Leroux, MSc

INSERM-CIC-1431

Besançon University Hospital 
F-25000 Besançon, France

E-mail f1leroux@chu-besancon.fr

Aurore Pugin, MSc

INSERM-CIC-1431

Besançon University Hospital

F-25000 Besançon, France

E-mail : avivot@chu-besancon.fr

\section{Caroline Savet, PhD}

Phisquare Institute

Transplantation Foundation

F-75015 Paris, France

E-mail : c1marmier@chu-besancon.fr

\section{Geoffroy Sainte-Claire Deville, MSc}

Phisquare Institute

Transplantation Foundation

F-75015 Paris, France

E-mail : geoffroy.sainteclairedeville.ext@aixial.com

\section{Didier Guillemot, MD, PhD}

INSERM UMR 1181 «Biostatistics, Biomathematics, Pharmacoepidemiology and Infectious Diseases » (B2PHI), 
F-75015 Paris, France

Institut Pasteur, UMR 1181, B2PHI

F-75015 Paris, France

University of Versailles St Quentin, UMR 1181, B2PHI

F-78180 Montigny-le-Bretonneux, France

AP-HP, Raymond Poincare Hospital,

F-92380 Garches, France

E-mail : didier.guillemot@pasteur.fr

Jacques Massol MD, PhD

Phisquare Institute

Transplantation Foundation

20, rue Saint Saëns

F-75015 Paris, France

E-mail : jacques.massol.ext@aixial.com

\section{Corresponding author:}

\section{Arnaud Fotso Kamdem}

Department of Pediatric Surgery

Besançon University Hospital 
F-25000 Besançon, France

Tel: +33 3812184 61, Fax: +33 381218640

Email: afotsokamdem@chu-besancon.fr

\begin{abstract}
Objective: The objective of the present study was to investigate the risk factors for intussusception (IS) a mong infants, including vaccination a gainst rot avirus.

Methods: Case-control study with systematic inclusion of all infants aged <1 year with suspected IS admit ted to emergency department $s$ in the eastern region of France between 1 April 2008 and 31 March 2012. Al 1 cases classed level 1 according to the Brighton classification were matched to 4 hospital controls. Two exposure windows were examined; exposure to the first dose of rotavirus vaccine in the 7 and in the 14 days prior to the occurrence of IS.
\end{abstract}

Results: A t otal of 115 cases were matched with 457 controls. The average vaccination coverage rate over the 4 years of study was $8.6 \%$. Rot a vir u s vaccine was not found to be significantly associated with the occurrence of IS in the 7 days (odds ratio (OR) not calculated; $\mathrm{p}=0.99$ ) and in the 14 days after administ $\mathrm{r}$ ation of one dose vaccine (OR 1.33, 95\% confidence int erval (CI) 0.14-12.82). Infant formula alone or combined with breastfeeding was associated wit h a n excess r isk of IS (OR 2.74, 95\% CI 1.10-6.79). A hist or y of gastroenterit is within 2 weeks prior to hospitalisation was also a ssociated wit h a $\mathrm{n}$ increa sed $\mathrm{r}$ isk (OR 2.24, 95\% CI 1.07-4.67).

Conclusion: Our study indicates that infant formula alone or combined with breastfeeding is an risk factor for IS. A small, non-significant increase in the risk of IS was observed after rotavirus vaccination, although the low vaccine coverage rate likely precluded detection of a significant increase in $r$ isk.

Key words: Int ussuscept ion - Infant s - case-cont rol st udy-rot a vir us vaccine $-\mathrm{r}$ isk fact or $\mathrm{s}$ 


\section{Authors' contributions :}

We confirm that all authors have made substantial contributions to the conception and design, or acquisition of data, or analysis and interpretation of data, or to the drafting of the article or its critical revision of important intellectual content. Further, we confirm that all authors have given final approval of the version to be published

and its submission to the European Journal of Pediatrics.

In particular, each author made the following contributions:

Arnaud Fotso kamdem : Dr Fotso Kamdem, coordinated the study, aided in data collection, wrote and reviewed the manuscript.

Chrystelle Vidal: Ms Vidal designed the study and carried out the analyses.

Lionel Pazart: Dr Pazart designed the study, revised and reviewed the initial manuscript of the study.

Aurore Pugin: Ms Pugin carried out the analyses.

Caroline Savet : Ms Savet was the clinical research assistant and carried out data collection.

Franck Leroux : Mr Leroux was data manager and aided in data collection. 
Geoffroy Sainte-Claire Deville: Mr Sainte-Claire Deville managed regulatory, ethical and administrative approach to the study, revised and reviewed the the initial manuscript of the study.

Didier Guillemot: Pr Guillemot conceptualized, designed the study, revised and reviewed the initial manuscript of the study.

Jacques Massol: Pr Massol conceptualized, designed the study, revised and reviewed the initial manuscript of the study.

and all authors approved the final manuscript as submitted.

\section{Acknowledgements:}

The authors thank the members of the diagnosis committee:

Professor Catherine Adamsbaum (University hospital Le Kremlin Bicêtre - Paris), Doctors Hélène Chappuy (Necker children’s hospital - Paris), Elisabeth Marc (University hospital Le Kremlin Bicêtre - Paris), Caroline Chamond (Hôpital Privé de l'Estuaire - Le Havre), Vincent Gajdos (University hospital Antoine Béclère - Clamart ).

The authors also thank Professors Marie-Laure Poli-Merol (American Memorial Hospital Reims), Didier Aubert (University Hospital Besançon), Rémi Besson (University hospital Lille); Doctors Aline Ranke (University hospital Nancy), Stephan Geiss, (Hospices de Colmar), Raphaël Moog (University hospital Strasbourg), Joséphine Lirussi-Borgnon (University Hospital Dijon), Emmanuel Pierre (General Hospital Metz-Thionvile); and Stéphanie François (CIC-BT, University hospital Besançon).

The authors also thank Fiona Ecarnot (EA3920, University Hospital Besancon, France) for translation and editorial assistance. 
Funding Source: This study was funded by grants from Sanofi Pasteur MSD and GlaxoSmithKline Biologicals SA (Study number: 109083). 
1 A Case-Control Study of Risk Factors for Intussusception Among Infants in Eastern

2 France after the Introduction of the Rotavirus Vaccine

3

4

5

6

7

8

\begin{abstract}
Objective: The objective of the present study was to investigate the $r$ isk factors for int ussuscept ion (IS) a mong infants, including vaccinat ion aga inst rotavirus.

Methods: Case-control study with systematic inclusion of all infants aged <1 year with suspected IS admitted to emergency depart ments in the eastern region of France between 1 Apr il 2008 and 31 March 2012. All cases classed level 1 according to the Brighton classificat ion were matched to 4 hospital controls. Two exposure windows were examined; exposure to the first dose of rotavirus vaccine in the 7 and in the 14 days prior to the occurrence of IS.
\end{abstract}

Results: A total of 115 cases were matched with 457 controls. The average vaccination coverage rate over the 4 years of study was $8.6 \%$. Rotavirus vaccine was not found to be significantly associated with the occurrence of IS in the 7 days (odds ratio (OR) not calculated; $p=0.99$ ) and in the 14 days after administration of one dose vaccine (OR 1.33, 95\% confidence interval (CI) 0.14-12.82). Infant formula alone or combined with breastfeeding was associated with an excess $r$ isk of IS (OR 2.74, 95\% CI $1.10-6.79$ ). A hist ory of gastroenterit is within 2 weeks prior to hospital isat ion was al so associated with an incr eased $r$ isk (OR 2.24, 95\% CI 1.07-4.67).

Conclusion: Our study indicat es that infant for mula alone or combined with breastfeeding is an $r$ isk factor for IS. A small, non-significant increase in the $r$ isk of IS was observed after rotavirus vaccination, although the low vaccine coverage rate likely precluded det ect ion of a signif icant increase in $r$ isk.

Key words: Int ussusception - Infant s - case-control st udy-rotavirus vaccine $-r$ isk fact or s

\title{
Abbreviations
}

IS, int ussuscept ion; OR, odds rat io; CI, confidence int er val ; CRF, case report for m; GERS, Groupement pour 1 'Élaborat ion et la Réal isat ion de Stat ist iques/Fr ench stat ist ics group; GUA, geographical unit s of analysis / Fr ench stat ist ics group; WA, weeks of 
32 a menorrhea; CNIL, Fr ench data protect ion authority / Co mmission Nat ionale Infor mat ique et 33 Libertés. 


\section{Introduction}

35

36

37

38

39

40

41

42

43

44

45

46

47

48

49

Int ussuscept ion (IS) is one of the ma in causes of abdominal obstruction in infants and young children. It is defined as the invaginat ion of one bowel segment int o another. The major ity of cases of IS do not have a pathologic lead point and are classified as primary or idiopathic int ussuscept ions. IS is a rare occurrence, with an incidence that var ies between countries [16]. The full spectrum of $r$ isk factors is not yet clearly defined. In 1999, the first vaccine aga inst rotavirus (Rotashield $®$, Wyeth Laborator ies, USA) was withdrawn fromt he market in the USA because it was found to be associated with an increased $r$ isk of IS [7]. The relative risk of IS during the first 3 to 7 days after administration of the vaccine was 58.9 [95\% confidence interval (CI) 31.7-109.6] after administration of the fir st dose, and 11.0 (95\% CI 4.1-29.5) after administration of the second dose [8]. New oral vaccines against rotavirus were subsequently developed based on an attenuated virus, namely Rotarix ${ }^{\circledR}$ (RV1, GlaxoSmithKl ine, Belgium), which has a 2-dose schedule, and RotaTeq ${ }^{\circledR}$ (RV5, Merck \& Co. Inc, USA), which has a 3-dose schedule. Recent post-marketing studies in different countr ies have shown a slight increase in $r$ isk of IS, part icularly after the first dose of these vaccines [9-14]. Both of these vaccines were introduced onto the market in France in 2006.

In this context, a large epidemiol ogical study (EPIstudy) was conducted in the Eastern region of France, with the primary object ive of invest igat ing the incidence of IS over a per iod of 4 years. The results of this epidemiological study have previously been published [6]. The a im of the present analysis was to invest igate the $r$ isk factors (including rotavirus vaccination)for the occurrence IS in infants aged $<1$ year.

\section{Methods}

\subsection{Study design}

We performed a case-control study based on a prospective, epidemiological registry designed to record the incidence of IS, and in which all infants aged less than one year with suspected IS were systematically recorded over a period of 4 years from 1 April 2008 to 31 March 2012 [6]. The current case-control study was performed in all hospitals with a pediatric emergency 
department in the greater eastern region of France (namely, Alsace, Burgundy, ChampagneArdenne, Franche-Comté and Lorraine). For each case, four controls were recorded.

The geographical area concerned by the epidemiological surveillance was defined to make it possible to estimate the incidence rate of IS with sufficient precision to detect an increase in annual incidence of around 50\% after the introduction of vaccination against rotavirus (Appendix 1).

\subsection{Patient cases and controls :}

Inclusion criteria for cases were: age $<12$ months, infants living in the study area during the study period, and presenting with suspected IS. Exclusion criteria were: age $\geq 12$ months, infants living outside the study area, patients with a prior episode of IS or occlusion, and parental refusal to consent. Cases were classified according to the Brighton collaboration definition [15] by an independent expert committee composed of radio-paediatricians, paediatricians, emergency physicians and paediatric surgeons, as level 1 (confirmed cases), level 2 (probable), level 3 (possible) and level 4 (insufficient information for classification), based on major and minor clinical and radiological criteria (Appendices 2 and 3).

Only level 1 cases were retained for this case-control study. Each case was matched with four hospital controls for sex, age ( \pm 1 week), admission period (one month before or after the admission of the case), and centre. Control subjects were infants $<12$ months who admitted for minor surgery, non-chronic disease, 1 iving in the study area dur ing the study per iod and not present ing suspected IS. Exclusion criteria for controls were: age $\geq 12$ months, infants living outside the study area, length of stay in excess of 2 weeks in the ward, a history of IS or occlusion, and parental refusal to consent.

\subsection{Data Collection and Study Variables}

Data were collected by the investigator at the time of the infant's admission to the emergency ward with suspected IS, or to the hospital ward, using a standardized case report form.

We recorded socio-demographic characteristics (date of birth, sex, weight and height at birth, weight and height at admission); as well as medical history (Meckel's diverticulum, tumour (intestinal polyp), cystic fibrosis, intestinal duplication, vascular intestinal malformations, 
Hirschsprung disease, prior history of abdominal surgery); clinical signs (unusual crying, abdominal pain, refusing bottles, vomiting, lethargy, pallor, coma, convulsions, hypovolemic shock, presence of blood in the nappy or on rectal examination, palpable abdominal mass, abdominal distension, or abnormal abdominal sounds); additional examinations (abdominal X-ray, echography, contrast enema, abdominal computed tomography (CT scan); and type of reduction (therapeutic enema or surgery), and outcome.

Variables for inclusion in the analysis were: signs of malnutrition (yes/no); history of infection within the previous 2 weeks (yes/no) and by type of infection: gastroenteritis (defined as the occurrence of a decrease in the consistency of stools (loose or liquid) and/or an increase in the frequency of evacuations ( $\geq 3$ in 24 hours), with or without fever or vomiting[16]), other, none; any medications received in the previous 2 weeks (defined as intake of any medication or pharmacological substance within the 2 weeks prior to hospitalization) (yes/no) ; concomitant disease in the 2 weeks prior to IS diagnosis (yes/no for each of: ear/nose/throat disorders, respiratory disorders, digestive disorders, other, none ); weight at admission (both in categories and as a continuous variable); height at admission (in categories and as a continuous variable); gestational term (as a continuous variable, and in categories: born at term [(gestation >37 weeks of amenorrhea (WA) or premature (22-37 WA)]; type of feeding in 3 categories (exclusive breastfeeding, infant formula, or mixed feeding (i.e. infant formula plus breastfeeding); introduction of solid food (yes/no), and rotavirus vaccine status (vaccinated/ non-vaccinated). Exposure to rotavirus vaccine was evaluated based on risk periods considered after administration of the first dose (0-2 months), the second dose (3-4 months), and the third dose (5-11 months) (RV5 vaccine).

For cases, the risk period was defined as the difference between the date of occurrence of IS (defined as the date of diagnosis) and the date of vaccination. For controls, the risk period was defined as the difference between the reference date on which the matched control subject was exactly the same age as the case patient at the time of hospitalization, and the date of rotavirus vaccination. The period not-at-risk in vaccinated children was used as the reference for the calculation of ORs.

Vaccine coverage was calculated using statistics from the French statistics group (GERS) (Groupement pour l'Élaboration et la Réalisation de Statistiques) for the period from April 2008 to March 2012, based on the number of vaccine doses dispensed by pharmacies and hospitals. Data were aggregated based on the list of geographical units of analysis (GUA) 
126

127

Coverage rate $=\frac{\text { volume of boxes delivered to pharmacies by type of vaccine } / \text { number of doses per vaccine }}{\text { Size of the birth cohort }}$

128 The volume of boxes delivered corresponds to the total number of single-doses of vaccine.

129 This calculation assumes that all children in the cohort receive the full dose schedule before

130 the age of one year.

131

132

133

134

135

136

137

138

139

140

141 The first phase of analysis consisted in descriptive analysis of the study population (idiopathic

142 cases). The second phase investigated risk factors for IS through the case-control study. The

143 following analyses were performed:

144

145

146 Univariate analysis by logistic regression was performed for all factors listed (predisposing

147 factors, risk factors) and adjusted for the matching variables. Qualitative variables were 148

\subsection{Data management}

Data were ent ered in dupl icat e before analysis.

The exhaust iveness of data collect ion was ver ified using capturer eca pture analysis (LincolnPetersen est imation) [17], which compared information from the hospital informatics databases to data fromt he EPIst udy [6].

\subsection{Statistical analysis}

\subsubsection{Primary analysis}

compared using the chi square test. Odds ratios (OR) are presented with 95\% Confidence Intervals (CI). Multivariate analysis by conditional logistic regression using stepwise selection was performed; all variables that had a p-value $<0.20$ by univariate analysis were included in the model. 
154 One of the risk factors for which we sought to investigate the potential relation with IS was 155 receipt of an oral vaccine against rotavirus. We considered that on average, 3 to 4 confirmed cases of IS would be included per month over the 4 years of the epidemiological surveillance

157

158

159

160

161

162

163

164

165

166

167

168

169

170

171

172

173

178 The parents who agreed to participate in the study received information about the study from 179 the investigating physician in a dedicated meeting with delivery of a factsheet. Given the non180 [18]. In the primary analysis, we made no distinction between vaccines; and the doses were considered all together. We planned to perform secondary analyses, if the number of cases recruited was sufficient, according to the type of vaccine received (RV1 or RV5), number of doses received $(1,2$, or 3$)$ and the time window of exposure as per the study by Murphy et al [8] (appendix 4). The prospective inclusion of 156 confirmed cases, each matched to 4 controls, made it possible to estimate the minimum detectable OR at 1.74 for an increase in risk related to rotavirus vaccination, based on the assumption of a vaccine coverage rate of $30 \%$. For reasons related to statistical power, two exposure windows were examined: exposure to the first dose of rotavirus vaccine in the 7 days prior to the occurrence of IS and; the exposure to any dose of rotavirus vaccine in the 14 days prior to the occurrence of IS.

To investigate the relation between vaccination against rotavirus and IS, we used univariate and multivariate conditional logistic regression to estimate ORs for IS during the predefined risk periods. All variables with p-value $<0.20$ by univariate analysis were included in the multivariate model, and were removed in a stepwise manner if their absence failed to affect the OR for IS after vaccination by $10 \%$ or more [8].

All analyses were performed using SAS version 9.3 (SAS Institute Inc., Cary, NC, USA).

The study was performed and reported in accordance with the STROBE criteria and recommendations[19].

\subsection{Ethics Statement} interventional nature of the study, oral consent was obtained, and written informed consent 
181

182

183

184

185

186

187

188

189

190

191

192

193

194

195

196

197

198

199

200

201

202

203

204

205

206

207

208

was not required in accordance with current French legislation (article L 1121-1 du Code de la Santé publique).

The protocol was approved by the Advisory Committee for the processing of data in health research in the French Ministry for Research on 6 April 2006 and by the French data protection authority under the number 906 127, on 18 August 2006.

\section{Results}

\subsection{Study population}

A total of 145 cases were included in the ma in epidemiol ogical st udy. Of these, $115(79.31 \%)$ were classified as a level $1,8(5.51 \%)$ as level $2,7(4.82 \%)$ as level 3 , and $15(10.34 \%)$ as level 4 ( previous publication [6]). The 115 level 1 cases were matched to 457 in-hospital controls for the pur poses of the present study.

Among the population of cases, $58.3 \%$ of the infants were boys, with a boy-girl sex rat io of 1.4. Table 1 shows the distribution of clinical signs among the cases. Only 20 infants (17.39\%) had the full symptom triad associating abdominal pain, vomit ing and rectal bleeding.

The most frequently used complementary examination for the diagnosis of IS was echography, which was used to confir m diagnosis in 114 (99.13\%). In 78 (67.83\%) infants, radiological reduct ion was complete (Appendix 5). Surgical treatment was perfor med in 37 $(32.17 \%)$ infant s. The median length of hospital stay was 3 days [IQR, 2-5]. No pat ient died.

3.2. Risk factor assessment

The result s of ther isk factor assessment are shown in Tables 2 and 3.

Infant for mula alone or with breast mil $k$ was associated with an excess $r$ isk of IS (adjust ed OR 2.74; 95\%CI 1.10-6.79) as compar ed to breast feeding alone. 
A hist ory of gastroent er tis was al so found to be associat ed with an excess $r$ isk of IS (adjust ed OR 2.24; 95\%CI 1.07-4.67) compared to no history of gastroent er $\mathbf{t}$ is in the 2 weeks pr ior to hospital admission. The exist ence of concomitant disease was associated with a reduct ion in ther isk of having IS (adjusted OR 0.20; 95\% CI $0.12-0.34$ ).

\subsection{Assessment of rotavirus vaccine as a risk factor}

During the study period, 12 cases of IS were recorded in infants who had received at least one dose of rotavirus vaccine ( $5 \mathrm{RV} 5,7 \mathrm{RV} 1$ ). Among the controls, 42 infants had received at least one dose of vaccine. The average vaccination coverage rate over the 4 years of study was $8.6 \%$. Table 4 shows the vaccine coverage rates per year. Only one case of IS occurred during the 2 weeks after administration of a first dose of the vaccine.

Figure 1 shows the intervals between the administration of a dose of rotavirus vaccine and the occurrence of IS among the cases, and between injection of a dose of rotavirus vaccine and the reference date in controls.

In primary analysis, rotavirus vaccination was not found to be significantly associated with the risk of IS, either after administration of a first vaccine dose within the previous 7 days, or after any vaccine dose within the previous 14 days in univariate analysis (Table 2).

In secondary analysis, after adjustment for breastfeeding and presence of concomitant disease in the 2 weeks prior to hospital admission, there was no significant impact of rotavirus vaccination on the risk of IS (OR 1.16, 95\% CI 0.58-2.30), r egardl ess of the time elapsed bet ween receipt of any dose of the vaccine, and occurrence of IS (maximum $t$ ime observed = 189 days).

\section{Discussion}

To the best of our knowledge, this case-control study is the first in France to provide new insights into the risk factors for IS.

Our findings show a predominance of boys in the study population, in line with previous reports in the literature [18]. The clinical signs presented by the children in our cohort were 
comparable to those previously described in other reports [20], with vomiting and abdominal 239 pain being the most frequent complaints.

240 In around one third of cases, surgery was necessary to achieve reduction of IS, either after a 241 failed attempt at radiological reduction, or as first-line therapy. The proportion of IS cases 242 treated by surgery varies widely, ranging from 12 to $88 \%$ according to different reports in the 243 literature [3,21]. Late management (beyond 24 hours after onset) could contribute to the high 244 rate of surgery observed in certain reports [22,23].

245 After adjustment, risk factor analysis in our study suggests the implication of infant formula in the occurrence of IS in infants. The implication of infant formula in the occurrence of IS in infants has previously been reported by a US case-control study that included 429 cases and 1763 controls, with an increased risk observed in infants who consumed cow's-milk formula [24]. This could be explained by the risk of allergy to the proteins in cow's milk, with the development of antibodies, a chronic immunological reaction, and hypertrophy of the Peyer's 251 patches [25].

We observed a significant relation between IS and the presence of gastroenteritis during the 2 weeks prior to IS, with a twofold increase in risk in those with a recent history of gastroenteritis. These findings are in agreement with other reports in the literature [26,27]. The role of rotavirus infection in the occurrence of IS remains controversial [28-30], and the conflicting results between studies could be explained by the lack of statistical power or the different methodologies used.

Unlike other studies [31][32], our study shows that the existence of concomitant disease in the 2 weeks prior to IS paradoxically had a significant protective effect on the occurrence of IS. This could be due to a possible bias described by Berkson [33] that is inherent to case-control studies performed in the hospital context. Indeed, the choice of a group of hospital controls incurs the risk that this group would be composed of patients who are more exposed than the general population to the risk under consideration in the study, i.e. in our case, the existence of concomitant disease. In light of this, the use of non-hospital controls could be considered as a possible alternative. However, this in turn would have exposed to a risk of selection bias, with the risk that the physician, who would be aware of the patient's vaccination status, would give precedence to children who had been vaccinated, thus leading to potential underestimation of this risk factor. Choosing hospital ized children as controls al so generat es a 
risk of confusion bias if, for example, control s had been chosen on their vaccinat ion status or according to the type of feeding they received. To minimize bias in our study, in particular select ion bias, cases and controls were matched for age, sex and centre of inclusion, based on the assumpt ion that children in a given region would all be referred to same large university hospital,thus reflect ing the general populat ion of chil dren of the sa me age.

275

Regarding a possible relation between rotavirus vaccination and IS, our findings showed a non-statistically-significant increase in the risk of IS after administration of one dose of vaccine in the 14 days prior to hospital admission, by univariate analysis, and also after one first dose of vaccine, with either time-window of exposure. Despite the different study design and methodological approach used in our study, our results are nonetheless in line with those of the literature. Reports from other countries have also shown an increased risk especially in the first week after administration of the first dose of the vaccine. For example, in a study from the Unit ed States, 124 cases of IS were recorded, of which 5 occurred dur ing the per iod at $r$ isk, and the attributable $r$ isk was estimated at 1.1 (95\% CI 0.3-2.7) dur ing the 7 days following inject ion of the fir st dose of the vaccine (RV5) [14]. In an Austral ian study of 306 cases, the vaccine attributabler isk for IS was est imat ed to be 4.3 (95\% CI 0.8-23.3) cases per 100,000 children vaccinated for RV1, and 7.0 (95\% CI, 1.5-33.1) cases per 100000 for RV5 [12]. Pat el et al showed an increased $r$ isk of IS after RV1 vaccine dur ing the week following the fir st vaccine dose with an OR of 5.8 (95\%CI 2.6-13.0) in a Mexican study of 285 cases, while a Brazilian study of 330 cases showed a non-significant increase in risk (OR 1.4, 95\%CI 0.4-4.8) [10]. In our study, the low number of cases combined with the low vaccine coverage rate 1 ikely precluded detection of a significant increase in the risk of IS. A metaanalysis by Rossillon et al [34] of the main post-marketing studies reported a relative risk of IS after the first dose of rotavirus vaccine of 5.4 (95\% CI 3.9-7.4) for the RV1 and 5.5 (95\%CI 3.3-9.3) for RV5. The risk is lower after the second dose, with ORs of 1.8 (95\% CI 1.3-2.5) and 1.7 (95\%CI 1.1-2.6) for RV1 and RV5 respectively. We also found that the risk decreased, albeit remaining non-significant, after adjustment for breast feeding and presence of concomitant disease within the 2 weeks prior to hospitalization, suggesting a protective role for breastfeeding.

We also noted a significant relation between the occurrence of acute gastroenteritis during the 2 weeks prior to IS, with a two-fold increase in risk of IS. In our multivariate analysis, we considered gastroenteritis as a variable of interest, and forced this variable in the model, despite a p-value of 0.31 by univariate analysis. This choice was based on previous literature 
303 data reporting a significant association between gastroenteritis and IS, and in this regard, our 304 findings are in line with previous publications [18] [26].

305 One of the strengths of this study is the quality of the data recorded. Indeed, exhaustiveness of 306 the recorded data was verified using diagnostic codes from the medical informatics systems 307 with capture-recapture analysis [17,35], and showed excellent overall exhaustiveness. A 308 further strength is the reliable quality of the data thanks to systematic monitoring and quality 309 control systems implemented to ensure the data recorded were verified and accurate.

310 The main limitation of our study is the lack of statistical power due to poor vaccine coverage rates. There are two main reasons for this poor vaccine coverage. First, at the time of the study, there were no recommendations regarding the rotavirus vaccine from the national health authorities and therefore no reimbursement for this vaccine by the national health insurance system .Secondly, scepticism in relation to vaccination in general is highly prevalent in France [36]. This attitude probably impacted negatively on the power of this study, and more generally, poses a problem for the statistical power of analyses linked to risk factors where exposure is the lowest. Finally, there may be pot ent ial for residual confounding.

\section{Conclusion}

321 This study highl ight s potent ial $r$ isk factors impl icated in the occurrence of IS. The occurrence 322 of acute ga stroenter $\mathbf{t}$ is in the 2 weeks pr ior to hospital izat ion is a signif icant $r$ isk factor for IS. 323 Infant formula alone or combined with breastfeeding was also found to be a significant risk 324 factor for the occurrence of IS. The limited statistical power and the low vaccine coverage 325 likely preclude detection of a significant increase in the risk of IS related to rotavirus 326 vaccination. 


\section{Acknowledgements:}

329 The aut hor s thank the member s of the diagnosis committee:

330 Professor Cather ine Adamsbaum (University hospital Le Kreml in Bicêtre - Par is), Doctors

331 Hé ène Cha ppuy (Necker children's hospital - Par is), E isabeth Marc (University hospital Le

$332 \mathrm{Kr}$ eml in Bicêtre - Par is), Carol ine Chamond (Hôpital Privé de l'Estua ire - Le Havre), Vincent

333 Gajdos (Univer sit y hospital Ant oine Bécl à̀ e - C amart ).

334 The authors also thank Professors Marie-Laure Pol i-Merol (Amer ican Memor ial Hospital 335 Reims), Didier Aubert (University Hospital Besançon), Rémi Besson (University hospital 336 Lille); Doctors Al ine Ranke (University hospital Nancy), Stephan Geiss, (Hospices de 337 Col mar), Raphä Moog (University hospital Strasbourg), Joséphine Lirussi-Borgnon 338 (University Hospital Dijon), Emmanuel Pierre (General Hospital Metz-Thionvile); and 339 St éphanie François (CIC-BT, Univer sity hospital Besançon).

340 The authors al so thank Fiona Ecarnot (EA3920, University Hospital Besancon, France) for 341 translation and edit or ial assistance.

342 Financial Disclosure: The authors have indicated they have no financial relationships 343 relevant to this art icle to disclose.

344 Conflict of Interest: The author s have indicated they have no pot ent ial confl icts of int erest to 345 disclose.

346 Funding Source: This study was funded by grants from Sanofi Pasteur MSD and 347 GlaxoSmithKline Biologicals (Study number: 109083). 


\section{References}

[1] Sa mad L, Cort ina-Borja M, Bashir HEl, Sut cl iffe AG, Marven S, Camer on JC, et al. Int ussuscept ion incidence among infants in the UK and Republ ic of Ir el and: a pre-rotavir us vaccine prospective surveil lance st udy. Vaccine 2013;31:4098-102. d oi:10.1016/j.va c cine .2013.06.084.

[2] Jenke AC, Kl a a ssen-Miel ke R, Zil ba uer M, Heininger U, Tr a mpisch H, Wir th S. Int ussuscept ion: incidence and $t r$ eat ment -insight $\mathrm{s}$ from the nat ion wide Ger man surveil 1 ance. J Pediat r Gast roent er ol Nut r 2011;52:446-51. d oi:10.1097/MPG.0b013e31820e1bec.

[3] Buet tcher M, Baer G, Bonhoeffer J, Scha ad UB, Heininger U. Thr ee-year surveil lance of int ussuscept ion in children in Swit zerland. Pediat $\mathrm{r}$ ics 2007;120:473-80. d oi:10.1542/ped s.2007-0035.

[4] Chen YE, Beasley S, Grimwood K, New Zeal and Rot avir us St udy Group. Int ussuscept ion and rot avirus a ssociated hospit al isat ion in New Zeal and. Ar ch Dis Chil d 2005;90:1077-81. doi:10.1136/a dc.2005.074104.

[5] Just ic e FA, Auldist AW, Bines JE. Int ussuscept ion: $\mathrm{t} r$ end $\mathrm{s}$ in $\mathrm{cl}$ in ic a 1 present at ion and management. J Gast roent er ol Hepat ol 2006;21:842-6. d oi:10.1111/j.1440-1746.2005.04031.x .

[6] Fot so Kamdem A, Vidal C, Pazart L, Ler oux F, Pugin A, Savet C, et a 1 . Incidence of acute int ussuscept ion a mong infant $\mathrm{s}$ in easter $\mathrm{n}$ France: result s of the EPIst udy t rial. Eur J Pediat r 2017;176:301-9. doi:10.1007/s00431016-2838-z.

[7] Centers for Disease Control and Prevention (CDC). Wit hdrawal of rot a virus vaccine recommendation. MMWR Morb Mor tal Wkl y Rep 1999;48:1007.

[8] Mur phy T V, Gargiullo PM, Massoudi MS, Nel son DB, Juma a n AO, Ok or o CA, et al. Int ussuscept ion a mong infant s given an or al rotavirus vaccine. $\mathrm{N}$ Engl J Med 2001;344:564.

[9] Leino T, Ol $1 \mathrm{gr}$ en J, St $\mathrm{r}$ ömberg N, El onsalo U. Evaluat ion of the Int ussuscept ion Risk after Pent avalent Rot a virus Vaccination in Fin nish Inf a nt s. PLoS One 2016;11:e0144812. doi:10.1371/jour na 1 .pone.0144812.

[10] Pa tel MM, López-Coll a da VR, Bul hões MM, De Ol iveir a LH, Ba ut ist a Már quez A, Fl annery $\mathrm{B}$, et a 1 . Int ussuscept ion $\mathrm{r}$ isk and heal $\mathrm{th}$ benefit $\mathrm{s}$ of rot avirus vaccinat ion in Mexico and Brazil. N Engl J Med 2011;364:2283-92. d o i:10.1056/NEJMo a 1012952.

[11] Rh a B, Tat e JE, Weint $r$ a ub E, Haber P, Yen C, Pa tel M, et a l. Int ussuscept ion following rotavirus vaccinat ion: an updated review of the avail able evidence. Expert Rev Vaccines 2014;13:1339-48. d o i:10.1586/14760584.2014.942223.

[12] Carl in JB, Macart ney KK, Lee KJ, Quinn HE, But ter y J, Loper t R, et a 1 . Int ussuscept ion $r$ isk and disea se prevention associat ed wit h r ot a virus $v$ accines in Aust $r$ alia's Nat ional Immunizat ion Program. Cl in Infect Dis 2013;57:1427-34. doi:10.1093/cid/c it 520.

[13] But ter y JP, St a ndish J, Bines JE. Int ussuscept ion and rot a vir us vaccines: consensus on benefit s out weighing recognized risk. Pediat $r$ Infect Dis $J$ 
[14] Yih WK, Lieu TA, Kulldorff M, Mart in D, Mc Mahil l-Wal r a ven CN, Pl at t R, et a l. Int ussuscept ion $r$ isk after rot a vir us vaccinat ion in U.S. infant $\mathrm{s}$. N Engl J Med 2014;370:503-12. doi:10.1056/NEJMo a 1303164.

[15] Bines JE, Kohl KS, For ster J, Zanardi LR, Davis RL, Hansen J, et al . Ac ut e int ussuscept ion in infants and children as an adverse event following immunization: case definit ion and guidel ines of dat a collect ion, analysis, and present at ion. Vaccine 2004;22:569-74.

[16] Guar ino A, Ashkenazi S, Gendrel D, Lo Vecchio A, Sha mir R, Szajewska H. European societ y for pediat $r$ ic gastroent erology, hepatology, and nut $r$ it ion/european societ y for pediat $r$ ic infect ious diseases evidencebased guidel ines for the management of acute gastroenter it is in chil dren in Europe: Update 2014. J Pediat r Gast roent er ol Nut r 2014;59:13252. d oi:10.1097/MPG.0000000000000375.

[17] Böhning D, Pat il ea V. A capt ur e--r ecapt ure a pproach for screening using $\mathrm{t}$ wo diagnost ic test $\mathrm{s}$ with avail abil it $\mathrm{y}$ of disease stat us for the test posit ives onl y. J Am St at Assoc 2008;103.

[18] Bines J, Ivanoff B. Acute int ussuscept ion in infant $s$ and children. Incidence, clinical present at ion and management: a global perspective. World Heal Organ Dep Vaccines Biol Geneva, Oct 2002, WHO/V\&B/0219 2002.

[19] von El m E, Al t man DG, Egger M, Pocock SJ, Gøt zsche PC, Vandenbroucke JP, et al. The St rengthening the Report ing of Observational St udies in Epidemiol ogy (STROBE) St a t ement : guidel ines for $r$ eport ing observat ional st udies. Int J Sur g 2014;12:1495-9. d oi:10.1016/j.ijsu .2014.07.013.

[20] Bl a nch AJ, Per el SB, Acwor th JP. Pa ediat $r$ ic int ussuscept ion: epidemiol og y and out come. Emerg Med Aust r a 1 as 2007;19:45-50. doi:10.1111/j.17426723.2007.00923.x.

[21] Bines JE, Patel M, Parashar U. Assessment of Post 1 icensure Safet y of Rot a vir us Vaccines, wit h Empha sis on Int ussuscept ion. J Infect Dis 2009;200:S282. d o i:10.1086/605051.

[22] Khumjui C, Doung-ngern P, Ser mgew T, Smit suw an P, Jir a phong sa C. Incidence of int ussusception a mong chil dren 0-5 years of age in Thail and, 2001-2006. Vaccine 2009;27:F116-9. d o i:10.1016/j.va c c in e.2009.09.003.

[23] Navarro OM, Daneman A, Chae A. Int ussuscept ion: The Use of Del ayed, Repeated Reduction At $t$ empt s and the Management of Int ussuscept ion s due to Pahologic Lead Points in Pediatric Patient s. Am J Roent genol 2004. doi:10.2214/a jr .182.5.1821169.

[24] Johnson B, Gargiul 1 o P, Mur phy T V, Par a shar UD, Pat el MM. Sociodemographic and diet ary risk factors for nat ural infant int ussuscept ion in the United St at es. J Pediat r Gast roent erol Nut $r$ 2010;51:458-63. d oi:10.1097/MPG.0b013e3181d 3273f .

[25] Iyngkar a n N, Yadav M, Bo ey CG, La m KL. Sever it y a nd ext ent of upper small bowel mucosal damage in cow's mil k protein-sensit ive ent er opathy. J Pediat r Gast roent er ol Nut r 1988;7:667-74. doi:3183870.

[26] Mansour AM, El Kout by M, El Barbary MM, Mohamed W, Shehat a S, El Mohammady $\mathrm{H}$, et al. Enteric viral infections as potential $\mathrm{r}$ isk factors 
for int ussuscept ion. J Infect Dev Ct ries 2013;7:28-35.

[27] Nylund CM, Denson LA, Noel JM. Bacterial enter it is as a $r$ isk fact or for chil dhood int ussuscept ion: a ret rospect ive cohor t st udy. J Pediat r 2010;156:761-5. doi:10.1016/j.jped s.2009.11.026.

[28] Bahl R, Saxena M, Bhandari N, Taneja S, Mathur M, Parashar UD, et al. Population-based incidence of int ussusception and a case-control st udy to examine the associat ion of int ussuscept ion with natural rotavirus infection a mong indian chil dren. J Infect Dis 2009;200 Suppl:S277-81. d o i: $10.1086 / 605045$.

[29] El -Hodhod MA, Na s sar MF, Ezz El -Ar a b S, Ah med EF. Rot a vir us fecal antigen ret $\mathrm{r}$ ieval in infant il e int ussuscept ion. Eur $\mathrm{JCl}$ in Microbiol Infect Dis 2008;27:879-81. doi:10.1007/s 10096-008-0506-6.

[30] Vel ázquez FR, Luna G, Cedil 1 o R, Tor res J, Muñoz O. Na t ur a 1 r ot a vir us infection is not associated to int ussuscept ion in Mexican children. Pediat r Infect Dis J 2004;23:S173-8.

[31] Bines JE, Liem NT, Just ic e FA, Son TN, Kir kwood CD, de Ca mpo M, et a l. Risk factors for int ussusception in infant $s$ in Viet $n a m$ and Aust $r$ alia: a denovirus impl icated, but not rot avirus. J Pediat r 2006;149:452-60. d o i:10.1016/j.jped s.2006.04.010.

[32] Hsu HY, Ka o CL, Hu a ng LM, Ni YH, La i HS, Lin FY, et a l. Vir al et iol og y of int ussuscept ion in Ta iwanese chil dhood. Pediat $r$ Infect Dis J 1998;17:893-8.

[33] Berkson J. Limit at ions of the appl ic at ion of the fourfold cont ingency t able. Biomet rics Bull 1946;2:47-53. doi:10.2307/3002000.

[34] Rosil lon D, Buyse H, Fr iedl and LR, Ng S-P, Vel ázquez FR, Br euer T. Risk of Int ussuscept ion After Rot avirus Vaccination: Met a-analysis of Post 1 icensure St udies. Pediat r Infect Dis J 2015;34:763-8. d o i:10.1097/INF.0000000000000715.

[35] Hook EB, Regal RR. Capt ur e-r ecapt ure met hods in epidemiol ogy: met hods a nd 1 imit at ions. Epid emiol Rev 1995;17:243-64.

[36] Lar son HJ, de Figueir edo A, Xiahong Z, Schul z WS, Verger P, Johnst on IG, et al. The st at e of vaccine confidence 2016: gl obal insight s through a 67count ry survey. EBio Medic ine 2016. 
480

481

482 
483 Table 1. Distr ibut ion of cl inical sympt oms and signs, diagnosis method, reduct ion procedures 484 and outcomes for int ussuscept ion of cases (l evel 1 of Bright on Collaborat ion Cassification)

$\mathrm{n}=115 \%$

\section{Clinical symptoms}

Abdominal pain (Persistent and unused crying) 79

68.70

Pallor

56.52

Let hargy

64

55.65

Hy povol emic shock

8

6.96

Fever $\left(>38^{\circ} \mathrm{C}\right)$

5

Bl oody stool

38

Refusal of baby bottle

40

34.78

Vo mit ing

80

69.57

Bil ed-st a ined vomit ing

13

11.30

Const ipation and $1 \mathrm{ack}$ of $\mathrm{gas}$

Dehydrat ion

9

7.83

\section{Physical signs}

Abnormal or absent bowel sounds

10

8.70

Abdominal dist en sion

25

21.74

Abdominal mass

30

26.09

Blood on rectal exam

17

14.78 
488 Table 2 Univar iate analysis of ther isk fact or s for int ussuscept ion in infants

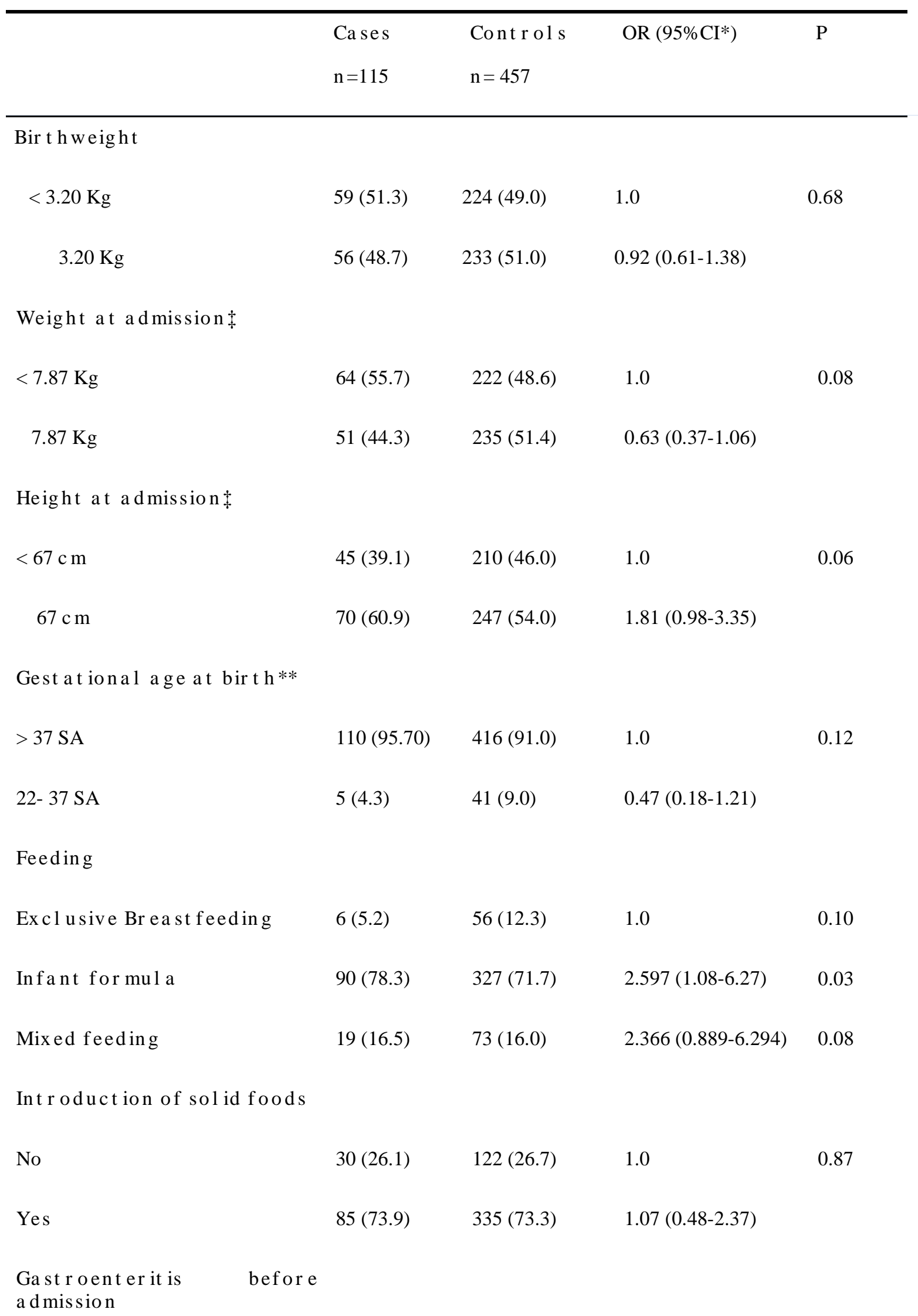


No

Yes

Any medications received in the previous 2 weeks
No
Yes
Concomit ant disease before

$81(70.4)$

$34(29.6)$

$235(51.4)$

$222(48.6)$

$0.41(0.26-0.66)$ a dmission

No

Yes

Exposure to first dose of rotavirus vaccine 7 days prior

No

Yes

Exposure to one dose of rotavirus vaccine 14 days prior

No

Yes
$86(74.8)$

$194(42.50)$

1

$<.01$

$29(25.2)$

$263(55.5)$

$0.23(0.14-0.37)$
$14(99.1)$

$1(0.9)$

$0(0.0)$
0.31

$1.42(0.72-2.79)$

*: CI, confidence int erval $\dagger$ mean \pm st andard deviation $=7.73 \pm 1.30$ (cases); $.77 \pm 1.59$ control s) ; OR 0.97, 95\% CI $0.7-$ 1.182 $\ddagger$ mean \pm st andard deviation $=67.44 \pm 5.59(\mathrm{cases}) ; .66 .68 \pm 6.47(\mathrm{cont} \mathrm{r}$ ol s $) ;$ OR $1.06,95 \% \mathrm{CI}$ 1.00-1.12

$* *$ mean \pm st andard deviation $=39.15 \pm 1.59($ cases $) ; .39 .02 \pm 2.27($ cont r o l s $) ;$ OR $1.03,95 \% \mathrm{CI}$ $495 \quad 0.93-1.13$ 
497 Table 3 Mult ivar iable logist ic regression model of the $r$ isk factors for int ussuscept ion in 498 infants

\begin{tabular}{|c|c|c|}
\hline & Adjusted OR (95\% CI) & $\mathbf{p}$ \\
\hline $\begin{array}{l}\text { Infant formula alone or } \\
\text { breastfeeding }\end{array}$ & wit h $2.74(1.10-6.79)$ & 0.03 \\
\hline Gastroenteritis before admission (yes vs no) $^{\mathrm{b}}$ & $2.24(1.07-4.67)$ & 0.03 \\
\hline Concomitant disease before admission (yes vs no) & $0.20(0.12-0.34)$ & $<0.01$ \\
\hline \multicolumn{3}{|c|}{$\begin{array}{l}\text { a: CI, confidence int erval, adjust ed for gestational term, Medication before hospitalization, } \\
\text { weight at admission, height at admission, gastroenteritis "within fifteen day, concomitant diseases. } \\
\text { The conditional logist ic regression was performed after examining } \\
\text { collinearit t o ascertain the independence of the covariates. } \\
\text { b : This variable was forced in multivariate analysis despite p }=0.31 \text { in } \\
\text { univariate because it was a known risk factor for IS. [18]- It is a variable of } \\
\text { clinical interest. }\end{array}$} \\
\hline
\end{tabular}




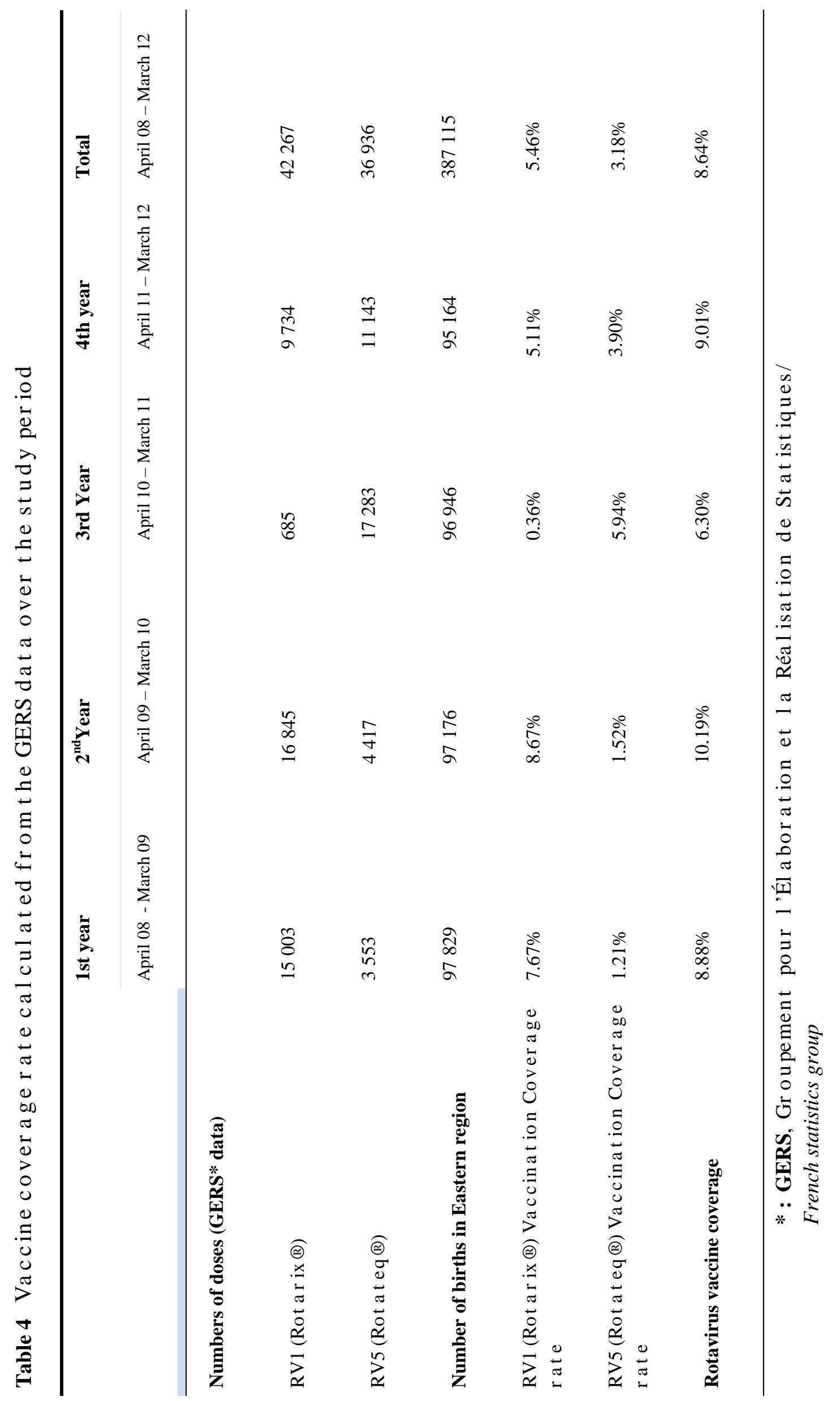

品 
$510 \quad$ Figure Legend:

511 Figure 1 Int erval between Rotavirus Vaccination and Hospital izat ion in cases and controls 512

513

514 

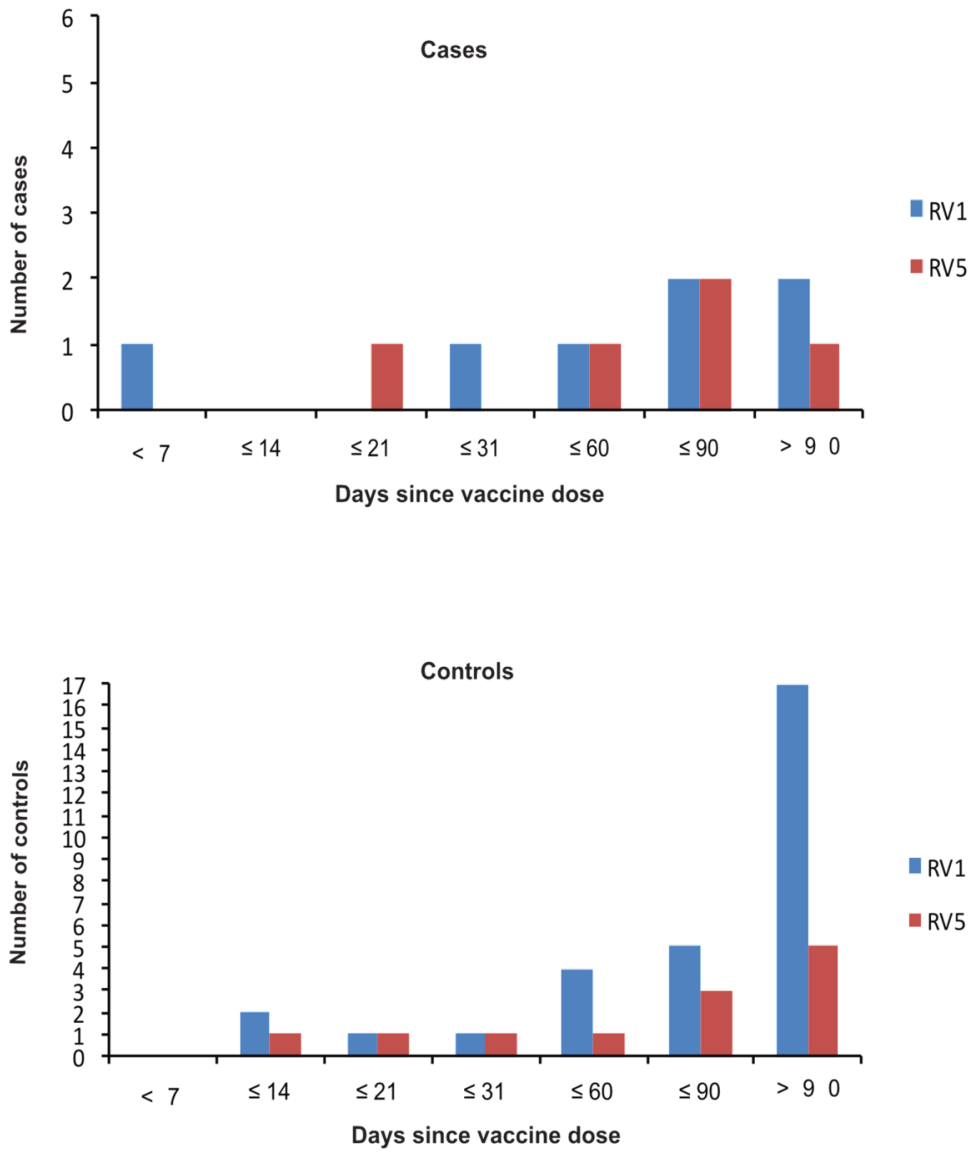